\title{
REGN-EB3: First Approval
}

\author{
Anthony Markham ${ }^{1}$
}

Published online: 11 January 2021

(c) Springer Nature Switzerland AG 2021

\begin{abstract}
REGN-EB3 (INMAZEB ${ }^{\circledR}$, Regeneron Pharmaceuticals) is a combination of three fully-human monoclonal antibodiesatoltivimab (REGN3470), maftivimab (REGN3479), and odesivimab (REGN3471) - that target Ebola virus glycoprotein. Based on the results of the PALM study conducted during an Ebola outbreak in the Democratic Republic of Congo, REGNEB3 was recently approved by the US FDA as a treatment for Ebola virus infection. This article summarizes the milestones in the development of REGN-EB3 leading to this first approval for the treatment of infection caused by Zaire ebolavirus (Ebola virus) in adult and paediatric patients.
\end{abstract}

Digital Features for this Adis Insight Report can be found at https://doi.org/10.6084/m9.figshare.13271699.

\section{REGN-EB3 (Atoltivimab/maftivimab/odesivimab-} ebgnINMAZEB ${ }^{\oplus}$ ): Key points

A monoclonal antibody combination is being developed by Regeneron Pharmaceuticals for the treatment of Ebola virus infection

Received its first approval 14 October 2020 in the USA

Approved for the treatment of infection caused by Zaire ebolavirus in adult and paediatric patients

\section{Introduction}

REGN-EB3 (atoltivimab/maftivimab/odesivimab-ebgn, INMAZEB $^{\circledR}$ ) is a co-formulated cocktail of three fullyhuman monoclonal antibodies; atoltivimab (REGN3470), maftivimab (REGN3479), and odesivimab (REGN3471),

This profile has been extracted and modified from the AdisInsight database. AdisInsight tracks drug development worldwide through the entire development process, from discovery, through preclinical and clinical studies to market launch and beyond.

Anthony Markham

dru@adis.com

1 Springer Nature, Mairangi Bay, Private Bag 65901, Auckland 0754, New Zealand developed by Regeneron Pharmaceuticals (Regeneron) for the treatment of Ebola virus infection. The product was originated via Regeneron's VelocImmune ${ }^{\circledR}$ platform and associated VelociSuite ${ }^{\circledR}$ technologies, with atoltivimab, maftivimab and odesivimab selected as the best candidates from a pool of Ebola virus glycoprotein-specific antibodies obtained from VelocImmune ${ }^{\circledR}$ mice that had been immunized with DNA constructs encoding the Ebola virus glycoprotein and/or recombinant purified virus glycoprotein (Makona strain) [1].

REGN-EB3 received its first approval on 14 October 2020 in the USA for the treatment of infection caused by Zaire ebolavirus in adult and paediatric patients [2,3]. The recommended dosage is $50 \mathrm{mg} / \mathrm{kg}$ of atoltivimab, $50 \mathrm{mg} /$ $\mathrm{kg}$ of maftivimab, and $50 \mathrm{mg} / \mathrm{kg}$ of odesivimab diluted and administered as a single IV infusion [3].

\subsection{Company Agreements}

In September 2015, Regeneron entered into an agreement with the Biomedical Advanced Research and Development Authority (BARDA) of the US Department of Health and Human Services (HHS) to develop, test and manufacture a monoclonal antibody therapy for the treatment of Ebola virus infection. Under the terms of the agreement HHS provided $\approx$ \$US17 million for preclinical development and antibody manufacturing intended to support an investigational new drug application (NDA) to the US FDA. The agreement included an option for an additional \$21 million to fund a phase I study in volunteers and further manufacturing and development studies [4].

In October 2017 HHS further agreed to provide $\approx$ \$US17 million in initial committed funding for development of REGN-EB3 with subsequent phases of funding earmarked 


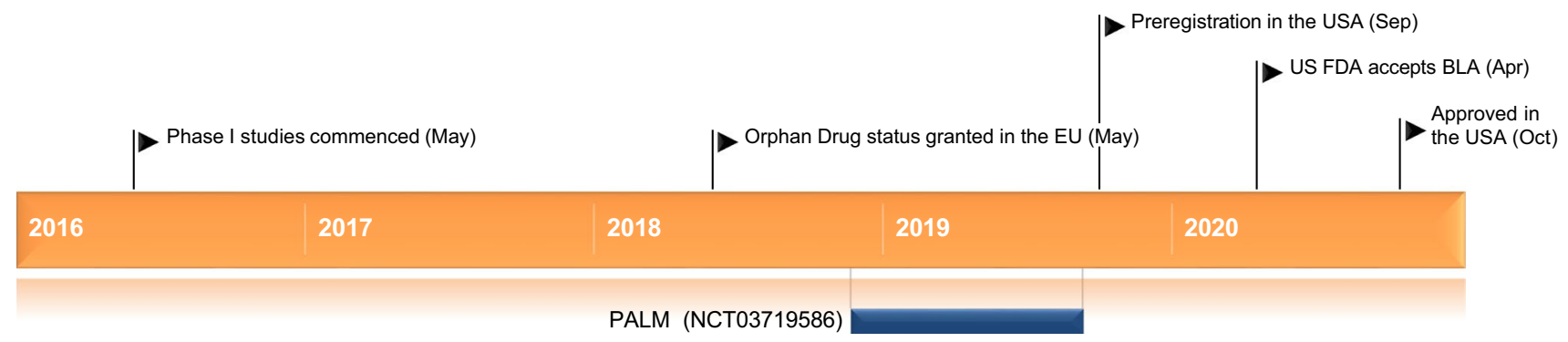

Key milestones in the development of REGN-EB3 for the treatment of Ebola virus infection. BLA Biologics Licence Application, FDA Federal Drug Administration

to support clinical development, a potential biologics licensing application (BLA) and initial procurement of the therapy for the US Strategic National Stockpile [5].

In July 2020 BARDA entered into an agreement to procure REGN-EB3 from Regeneron in keeping with the HHS goal of building national preparedness for public health emergencies. Regeneron expects to deliver an established number of treatment doses over the course of six years and anticipates payments of $\approx \$ 10$ million in 2021 and an average of $\$ 67$ million per year between 2022 and 2026 [6].

\section{Scientific Summary}

\subsection{Pharmacodynamics}

Using surface plasma resonance (SPR) atoltivimab, odesivimab and maftivimab had $K_{\mathrm{D}}$ values of 7.74, 8.42 and $2.97 \times 10^{-9} \mathrm{~mol} / \mathrm{L}$, respectively, for recombinant histidinetagged Makona strain Ebola virus glycoprotein ectodomain protein, indicative of high-affinity binding. Only odesivimab demonstrated specific binding to soluble virus glycoprotein, indicating that it binds within the first 295 amino acids of the common region of Ebola virus glycoprotein and soluble virus glycoprotein [1].

Atoltivimab, maftivimab and odesivimab did not compete for binding to Ebola virus glycoprotein when assessed using the Octet HTX system, and were shown to bind simultaneously to Ebola virus glycoprotein in a three-step sequentialbinding study performed using SPR. Single-particle, negative-stain electron microscopy indicated that each antibody binds to a different site on the glycoprotein molecule [1].

Atoltivimab and maftivimab neutralized pseudovirus particles in vitro (half maximal inhibitory concentration [ $\left[\mathrm{IC}_{50}\right]$ values 0.27 and $0.17 \mathrm{nmol} / \mathrm{L}$, respectively) with odesivimab having less effect. Together the three antibodies had an $\mathrm{IC}_{50}$ of $0.39 \mathrm{nmol} / \mathrm{L}[1]$.

In the rhesus macaque model of Ebola virus infection three doses of the atoltivimab, odesivimab and maftivimab cocktail on days five, 8 and 11 post-infection $(50 \mathrm{mg} / \mathrm{kg}$ total antibody per dose) provided complete protection from lethal disease, with placebo-treated animals succumbing by day 9 post-infection. In a similar study, a single $150 \mathrm{mg} / \mathrm{kg}$ dose of atoltivimab, odesivimab and maftivimab produced a similar result to that observed with the three $50 \mathrm{mg} / \mathrm{kg}$ dose regimen. In a third study in rhesus macaques designed to evaluate the minimal effective single dose of the atoltivimab, odesivimab and maftivimab cocktail $100 \mathrm{mg} / \mathrm{kg}$ was the lowest dose tested that gave best control of symptoms [1].

\subsection{Pharmacokinetics}

The pharmacokinetic profiles of atoltivimab, odesivimab and maftivimab have been studied in a double-blind phase I dose-escalation study in volunteers. Volunteers were randomized to receive $3 \mathrm{mg} / \mathrm{kg}(n=3), 15 \mathrm{mg} / \mathrm{kg}(n=$ $3), 60 \mathrm{mg} / \mathrm{kg}(n=6)$ and $150 \mathrm{mg} / \mathrm{kg}(n=6)$ doses of atoltivimab, odesivimab and maftivimab (administered together as a single IV infusion), or placebo $(n=6)$. Changes in serum concentration over time were biphasic for all three monoclonal antibodies, comprising an initial rapid distribution phase and a slow elimination phase. All three antibodies had a linear, dose-proportional pharmacokinetic profile, with similar dose-normalised maximum concentrations and $\mathrm{AUC}_{0-\text { inf }}$ across all four dose groups, and dose-independent overall mean $t_{1 / 2}$ values $(27 \cdot 3,21.7$ and 23.3 days for odesivimab, atoltivimab and maftivimab, respectively) [7]. 


\begin{tabular}{|c|c|}
\hline Alternative names & $\begin{array}{l}\text { Atoltivimab/maftivimab/odesivimab, atoltivimab/maftivimab/odesivimab-ebgn, REGN3470 (atoltivimab), } \\
\text { REGN3479 (maftivimab), REGN3471 (odesivimab), REGN 3470/3471/3479, REGN3470-3471-3479 }\end{array}$ \\
\hline Class & Antivirals, monoclonal antibodies \\
\hline Mechanism of Action & Antibody-dependent cell cytotoxicity, phagocyte stimulants, virus internalisation inhibitors \\
\hline Route of Administration & Intravenous \\
\hline Pharmacodynamics & $\begin{array}{l}\text { Atoltivimab, maftivimab and odesivimab had } K_{\mathrm{D}} \text { values of } 7.74,8.42 \text { and } 2.97 \times 10^{-9} \mathrm{~mol} / \mathrm{L} \text {, respectively, for } \\
\text { recombinant histidine-tagged Makona strain Ebola virus glycoprotein ectodomain protein }\end{array}$ \\
\hline Pharmacokinetics & Overall mean $t_{1 / 2}$ values $(27 \cdot 3,21.7$ and 23.3 days for odesivimab, atoltivimab and maftivimab, respectively \\
\hline \multicolumn{2}{|l|}{ Adverse events } \\
\hline Most frequent & Pyrexia, chills, tachycardia, tachypnoea, vomiting, hypotension, diarrhoea and hypoxia \\
\hline \multicolumn{2}{|l|}{ ATC codes } \\
\hline WHO ATC code & J05A-X (Other antivirals) \\
\hline EphMRA ATC code & J5B9 (Antivirals, others) \\
\hline Chemical Name & $\begin{array}{l}\text { Immunoglobulin G1, anti-(Zaire ebolavirus glycoprotein) (human monoclonal REGN3470 gamma1-chain), } \\
\text { disulfide with human monoclonal REGN3470 kappa-chain, dimer/ Immunoglobulin G1, anti-(Zaire ebola- } \\
\text { virus glycoprotein) (human monoclonal REGN3479 gamma1-chain), disulfide with human monoclonal } \\
\text { REGN3479 kappa-chain, dimer/Immunoglobulin G1, anti-(Zaire ebolavirus glycoprotein) (human mono- } \\
\text { clonal REGN3471 gamma1-chain), disulfide with human monoclonal REGN3471 kappa-chain, dimer }\end{array}$ \\
\hline
\end{tabular}

\subsection{Therapeutic Trials}

REGN-EB3 plus standard care was superior to standard care plus ZMapp against the Ituri Ebola virus variant in the PALM trial conducted during the 2018 Ebola virus disease outbreak in the Democratic Republic of Congo [8]. The trial was originally designed as a three arm study evaluating the efficacy of ZMapp, remdesivir and Mab114; however, the protocol was subsequently updated to include a REGN-EB3 arm, with data from this group compared only with those from patients in the ZMapp group enrolled on or after the time the REGN-EB3 group was added. Only data from this comparison are described below. Despite the extraordinary challenges encountered in conducting the trial (e.g. regional violence, unstable electrical power grid, transportation difficulties, history of high morbidity from other infectious diseases), a successful conclusion was achieved through careful planning, cooperation, support, and coordination from multiple organisations and support staff [8].

Patients were randomized to treatment with REGN-EB3 $150 \mathrm{mg} / \mathrm{kg}$ as a single infusion on day $1(n=155)$ or IV
ZMapp $50 \mathrm{mg} / \mathrm{kg}$ every third day beginning on day one for a total of three doses $(n=154)$. All patients also received standard care, comprising IV fluids, daily clinical laboratory testing, correction of hypoglycaemia and electrolyte imbalances, and administration of broad-spectrum antibiotic and antimalarial drugs [8].

The mortality rate at 28 days (primary endpoint) was $17.8 \%$ lower in the REGN-EB3 group than in the ZMapp group (95\% confidence interval, -28.9 to -2.9 ; $p=0.002$ ). The survival benefit observed in REGN-EB3 recipients was also evident in sensitivity analyses adjusted for potential baseline imbalances including duration of symptoms, nucleoprotein cycle threshold $(\mathrm{Ct})$ value, patient age, creatinine level, alanine and aspartate aminotransferase levels, and patient reported vaccination. The median time to the first negative result on RT-PCR assay for Ebola virus nucleoprotein was 15 days in REGNEB3 recipients compared to 27 days in the ZMapp group (secondary endpoint). For the purposes of this analysis patients who had died were considered as not having had viral clearance [8]. Key clinical trials of REGN-EB3 (Regeneron Pharmaceuticals)

\begin{tabular}{|c|c|c|c|c|c|}
\hline $\operatorname{Drug}(\mathrm{s})$ & Indication & Phase & Status & Location(s) & Identifier \\
\hline REGN-EB3, ZMapp & Ebola virus infection & $\mathrm{II} / \mathrm{III}$ & Completed & $\begin{array}{l}\text { Democratic Republic of } \\
\text { Congo }\end{array}$ & NCT03719586, PALM \\
\hline REGN-EB3 & Ebola virus infection (expanded access) & N/A & Recruiting & N/A & NCT03576690 \\
\hline $\begin{array}{l}\text { Atoltivimab, maftiv- } \\
\text { imab, odesivimab }\end{array}$ & $\begin{array}{l}\text { Tolerability and pharmacokinetics in } \\
\text { volunteers }\end{array}$ & I & Completed & USA & NCT02777151 \\
\hline
\end{tabular}




\subsection{Adverse Events}

Adverse events occurring during REGN-EB3 infusion in $\geq 10 \%$ of adult and paediatric patients participating in the PALM trial included pyrexia (elevation in fever) [occurring in 54 and 58\% of REGN-EB3 $(n=154)$ and control $(n=168)$ recipients, respectively], chills (39 and 33\%), tachycardia (20 and 32\%), tachypnoea (19 and 28\%), vomiting (19 and 23\%), hypotension (15 and 31\%), diarrhoea (11 and $18 \%$ ) and hypoxia (10 and $11 \%$ ) [3].

Selected grade 3 and 4 laboratory abnormalities with grade worsened from baseline for adult and paediatric patients participating in the PALM trial included sodium levels $\geq 154 \mathrm{mmol} / \mathrm{L}$ [occurring in 9 and $4 \%$ of REGNEB3 $(n=154)$ and control $(n=168)$ recipients, respectively], sodium levels $<125 \mathrm{mmol} / \mathrm{L}$ ( 7 and $11 \%$ ), potassium levels $\geq 6.5 \mathrm{mmol} / \mathrm{L}$ (13 and $12 \%$ ), potassium levels $<2.5 \mathrm{mmol} / \mathrm{L}$ ( 9 and $8 \%$ ), creatinine $\geq 1.8$ times upper limit of normal (15 and 23\%), alanine aminotransferase $\geq 5$ times upper limit of normal (10 and 14\%) and aspartate aminotransferase $\geq 5$ times upper limit of normal (21 and $18 \%$ ) [3].

No immunogenic responses to atoltivimab, maftivimab or odesivimab were detected at baseline or through to 168 days post-dose in any subjects participating in the phase I dose escalation trial described above [7].

\subsection{Ongoing Clinical Trials}

An expanded access protocol for emergency use of REGNEB3 is available for individuals in an Ebola endemic region with documented positive polymerase chain reaction for Ebola virus infection who are symptomatic (NCT03576690).

\section{Current Status}

REGN-EB3 received its first approval on 14 October 2020 for the treatment of Zaire ebolavirus (Ebola virus) infection in adult and paediatric patients in the USA [2].

\section{Declarations}

Funding The preparation of this review was not supported by any external funding.

Conflict of interest Changes resulting from any comments received during the peer review process were made by the authors on the basis of scientific completeness and accuracy. A. Markham is a contracted employee of Adis International Ltd/Springer Nature, and declares no relevant conflicts of interest. All authors contributed to the review and are responsible for the article content.

Ethics approval, Consent to participate, Consent to publish, Availability of data and material, Code availability Not applicable.

\section{References}

1. Pascal KE, Dudgeon D, Trefry JC, et al. Development of clinicalstage human monoclonal antibodies that treat advanced Ebola virus disease in nonhuman primates. J Infect Dis. 2018;218(Suppl 5):S612-26.

2. US Food \& Drugs Administration. FDA approves first treatment for ebola virus [media release]. 14 Oct 2020. https://www.fda. gov/news-events/press-announcements/fda-approves-first-treat ment-ebola-virus.

3. Regeneron Pharmaceuticals. INMAZEB ${ }^{\mathrm{TM}}$ (atoltivimab, maftivimab, and odesivimab-ebgn) injection, for intravenous use: US prescribing information. 2020. https://www.accessdata.fda.gov/drugs atfda_docs/label/2020/761169s000lbl.pdf. Accessed 6 Nov 2020.

4. Regeneron Pharmaceuticals. Regeneron announces agreement with BARDA for the development of new antibody treatment for Ebola [media release]. 21 Sep 2015. http://www.regeneron.com.

5. Regeneron Pharmaceuticals. Regeneron announces new collaborations with HHS to develop antibodies against Ebola, influenza and multiple other emerging pathogens [media release]. 2 Oct 2017. http://www.regeneron.com.

6. Regeneron Pharmaceuticals. BARDA procures regeneron's REGN-EB3 investigational Ebola treatment for national preparedness [media release]. $29 \mathrm{Jul} 2020$. www.regeneron.com.

7. Sivapalasingam S, Kamal M, Slim R, et al. Safety, pharmacokinetics, and immunogenicity of a co-formulated cocktail of three human monoclonal antibodies targeting Ebola virus glycoprotein in healthy adults: a randomised, first-in-human phase 1 study. Lancet Infect Dis. 2018;18(8):884-93.

8. Mulangu S, Dodd LE, Davey RT Jr, et al. A randomized, controlled trial of Ebola virus disease therapeutics. N Engl J Med. 2019;381(24):2293-303. 